\title{
Construction of Characteristic Town Brand Color Systems: Color Extraction Based on Regional Landscape Architecture
}

\author{
Fangyi MAO ${ }^{* 1, a}$, Pengcheng ZHAO ${ }^{1, b}$, Zhe $\mathrm{ZHU}^{1, \mathrm{c}}$ \\ ${ }^{1}$ Art School, Jiangsu University, Zhenjiang, Jiangsu, 202013, China
}

\begin{abstract}
The brand image design of characteristic towns already becomes the way to improve awareness and promote propaganda in many characteristic towns. However, during the brand color system construction of characteristic towns, the differences in natural geography and cultural landscape have resulted in universal differentiation of characteristic towns, but the brand color constructions are very similar and lack scientific basis or differences, and even deviate from the original intention of town brand building. Given the difficulty in the brand color system development of characteristic towns, we proposed a strategy to build the characteristic town brand color system according to the color extraction from regional landscape buildings. With the characteristic Xiaolan Town in Zhongshan City of Guangdong province as example, the features of natural landscape plants and architecture color design were extracted on basis of the comprehensive regional landscapes. The color library for color design was acquired through data analysis, and the colors of historical landscape buildings were integrated with the colors of modern science and technology elements. With the introduction of building graphs, the deep connection between color design and brand visual image was enhanced. This design strategy offers some scientific values and theoretical guidance for exploring the brand color design systems of characteristic towns and for guiding the innovative strategies of designers.
\end{abstract}

\section{Introduction}

Characteristic towns as a developing mode for small towns (Bajracharya, 1995) has been valued again in the Desakota theoretical mode (McGee, 1991), the urbanrural integration mode (Mike Douglass, 1991), the intelligent city mode (Giffinger et al., 2007) and the threedimensional urbanization mode (Toppeta, 2010) and has raised a heat wave of construction, exploitation and planning. Characteristic towns are generally defined as a new innovative and entrepreneurial development platform that possesses accurate industry positioning, rich cultural connotation, leisure tourism function and the corresponding functional areas and that integrates characteristic industries, emerging industries and various factors of economic development or various innovation elements (Li Qiang, 2015).

The principal part of brands is not only the products and services of an enterprise, but may also be a city, individuals and cultures (Kevin Lane Keller, 2009). A growing number of regions have created characteristic towns from the aspect of brands (Matthew Hurley, 2009) and have formed the unique and typical cognitive signs of certain towns. Thereby, the visual image design becomes a critical competitive part with their rivals. To build an independent and unique brand of characteristic towns, it is urgent to integrate the regional historical cultures (Inès Hassen \& Massimo Giovanardi, 2018), perceive the psychology of the public (Filareti Kotsi \& Ian Michael, 2018) and make use of modern media (Matilda Ståhl \& Hannah Kaihovirta, 2019). The characteristic town can be designed as a brand that is centered at the characteristic industries and cultures and that inherits and displays the local unique cultures (Wu Keyan, 2017) so as to guide the modern society and economic development into a new stable state and promote the urban-rural coordination.

The visual image design and planning is a visual way to build the characteristic town brand and also is the core content (Liz Farrelly, 2013). The visual image design of a characteristic town consists of two parts: the basic system design and the application system design. The contents of the basic system design include town logo, standard words, auxiliary graphics, standard colors and auxiliary colors, while the contents of the application system design include office supplies, graphics and multimedia publicity, guidance system, souvenir image and packaging design. In particular, colors play an indispensable part and bring people the direct vision sensory experience and convey the hierarchical information. The color design is used to exhibit the brand visual image of characteristic towns and to highlight the local cultural characteristics of towns (Zhu, 2005). With the natural convey and emotional appeal, the colors can directly and effectively excite the audience through the unique visual stimulus and mental feelings. Colors show us the spirits and alive souls of the unique towns (Johannes Itten, 1999) and maintain the visual image between unique

\footnotetext{
a1062401300@qq.com

b1184742584@qq.com

c337460060@qq.com
} 
towns and the brands.

In China, however, due to the ignorance of the "quality" of characteristic town brand image and the likelihood to follow the trends, the "number" of characteristics towns increased severely and the own regional landscape color features were neglected. Moreover, the traditional colors of historical buildings were abandoned, the color features of historical cultural information were obliterated, and the color characteristics of characteristic towns disappeared, which led to severe homogenization and ambiguous identities. Under the framework of regional landscape planning and design of characteristic towns and according to the industrial, cultural and environmental characteristics in small towns, attention should be paid to the significance and functions of the characteristic town brand color system construction (Highland, 2009). Together with the concepts of "color geography" (Jean - Philippe Lenclos, 1960), whether the basic identification and application system design scheme of characteristic town visual image can be refined by integrating the colors of historical landscape buildings and the colors of modern science and technology elements and by dynamically controlling the overall image and the the details of architecture materials, textures and colors? How to extract and apply the color features of regional landscape buildings during the visual image design process?

\section{Research method}

\subsection{Selection of research areas}

Xiaolan Town is located in the middle of the Pearl River Delta of Guangdong Province, and is the central town in north of Zhongshan City. In this study, the core zone of Xiaolan characteristic town was selected (Fig. 1). The study area is near the Longshan Park, Binghe Park and Xiaolan Government. This area enjoys convenient transportation, superior geographical position and industrial concentration. This is also the engine of regional characteristic town construction and enjoys rich historical cultural characteristics.

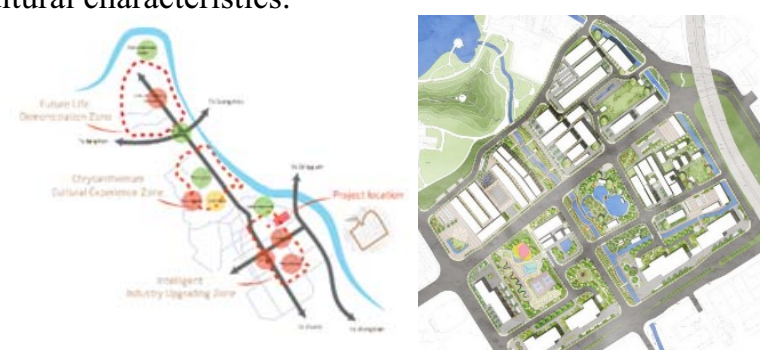

Figure 1: Location of core zone of Xiaolan Town

(1) Natural regional analysis: landscape patterns and "Shuiseza"

Xiaolan belongs to the subtropical monsoon climate and enjoys abundant rainfall throughout the year and flat terrains. The vegetation there mainly consists of droughttolerant tropical evergreen and deciduous broad-leaved trees. The common species include Melia azedarach L., Ficus altissima, Ficus microcarpa, Bombax malabaricum,
Rhodoleia championii Hook. f., Hibiscus macrophylla, Acacia confusa Merr., Delonix regia, and Cercis chinensis (Table 1). Xiaolan enjoys convenient traffic with the surrounding cites and has the state-level key stations. It also has rich surface water resources with rivers everywhere and is famous for the first large shore scenic spot - Shuiseza (Fig. 2).

Table 1 Common plant species in Xiaolan

\begin{tabular}{|c|c|c|c|c|}
\hline $\begin{array}{l}\mathrm{N} \\
\mathrm{o}\end{array}$ & $\begin{array}{c}\text { Tree } \\
\text { species }\end{array}$ & Flower color & Flowering time & Habit \\
\hline 1 & $\begin{array}{l}\text { Michelia } \\
\text { alba }\end{array}$ & White & $\begin{array}{l}\text { Spring, } \\
\text { summer }\end{array}$ & Evergreen \\
\hline 2 & $\begin{array}{l}\text { Michelia } \\
\text { champaca }\end{array}$ & Yellow & $\begin{array}{l}\text { Spring, } \\
\text { summer }\end{array}$ & Evergreen \\
\hline 3 & $\begin{array}{c}\text { Grevillea } \\
\text { robusta }\end{array}$ & Yellow & Summer & Evergreen \\
\hline 4 & $\begin{array}{l}\text { Syzygium } \\
\text { jambos }\end{array}$ & White, green & Summer & Evergreen \\
\hline 5 & $\begin{array}{c}\text { Cinnamom } \\
\text { um } \\
\text { burmanni }\end{array}$ & Light yellow & Spring & Evergreen \\
\hline 6 & $\begin{array}{c}\text { Sterculia } \\
\text { nobilis }\end{array}$ & White yellow & Summer & Evergreen \\
\hline 7 & $\begin{array}{c}\text { Callistemon } \\
\text { viminalis }\end{array}$ & Red & $\begin{array}{l}\text { Spring, } \\
\text { summer }\end{array}$ & Evergreen \\
\hline 8 & $\begin{array}{c}\text { Bombax } \\
\text { malabaricu } \\
\mathrm{m} \\
\end{array}$ & $\begin{array}{l}\text { Bright red, } \\
\text { orange }\end{array}$ & Winter, spring & Deciduous \\
\hline 9 & $\begin{array}{c}\text { Eriobotrya } \\
\text { japonica }\end{array}$ & Light yellow & Winter & Evergreen \\
\hline $\begin{array}{l}1 \\
0\end{array}$ & $\begin{array}{c}\text { Acacia } \\
\text { confusa } \\
\text { Merr. }\end{array}$ & Yellow & Summer & Evergreen \\
\hline $\begin{array}{l}1 \\
1\end{array}$ & $\begin{array}{c}\text { Bauhinia } \\
\text { blakeana } \\
\text { Dunn } \\
\end{array}$ & Purple & Winter & Deciduous \\
\hline $\begin{array}{l}1 \\
2\end{array}$ & $\begin{array}{l}\text { Cassia } \\
\text { surattensis } \\
\text { Burm. f. } \\
\end{array}$ & Yellow & Summer, fall & Evergreen \\
\hline $\begin{array}{l}1 \\
3 \\
\end{array}$ & $\begin{array}{c}\text { Delonix } \\
\text { regia }\end{array}$ & Red & Summer & Deciduous \\
\hline $\begin{array}{l}1 \\
4 \\
\end{array}$ & $\begin{array}{l}\text { Plumeria } \\
\text { rubra L. cv. }\end{array}$ & Plain yellow & Summer, fall & Deciduous \\
\hline $\begin{array}{l}1 \\
5 \\
\end{array}$ & $\begin{array}{c}\text { Crateva } \\
\text { formosensis }\end{array}$ & White & Spring & Deciduous \\
\hline $\begin{array}{l}1 \\
6\end{array}$ & $\begin{array}{c}\text { Ceiba } \\
\text { speciosa } \\
\text { St.Hih. }\end{array}$ & $\begin{array}{l}\text { White and } \\
\text { pink }\end{array}$ & Winter, spring & Deciduous \\
\hline
\end{tabular}

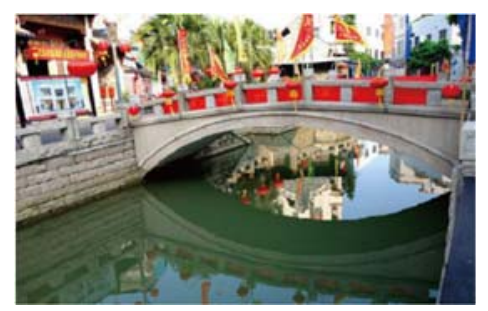

Figure 2: Characteristic "Shuiseza" of Xiaolan

(2) Human resource analysis: building styles/features and Lingnan cultures

Xiaolan was originally a part of Dalan City and was built since Song Dynasty, and thus has a history of more than 700 years. It has accumulated a rich history of Lingnan cultures. Because people in Xiaolan like planting and appreciating chrysanthemum, and holds annual chrysanthemum appreciation meetings, Xiaolan is known 
as "the town of chrysanthemum". The calligraphy and painting arts in Xiaolan have been inherited from generation to generation, and Xiaolan has many celebrities. Xiaolan is also known as "the hometown of Chinese folk arts (calligraphy and painting)". Xiaolan has reserved a part of ancient buildings (Fig. 3) and many unique customs and habits. Xiaolan has bred many dialect and folk activities from diverse cultures, such as Xiaolan chrysanthemum collections, colors above water, and dragon boat competition.

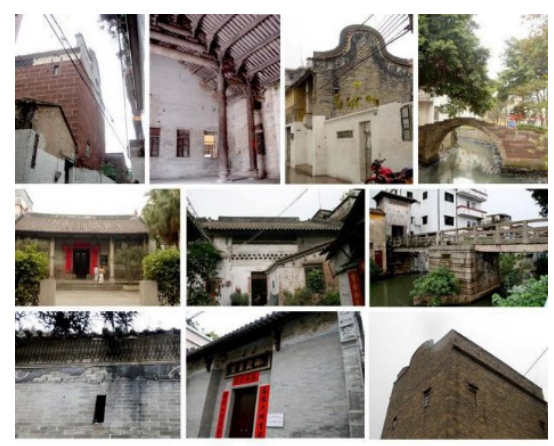

Figure 3: Historical buildings in Xiaolan

\subsection{Research Framework and Methodology}

The thoughts of this study are that with the characteristic Xiaolan Town as example and based on the regional landscape planning in the core zone, we extracted the features of natural landscape plants and architecture color design. The color library for color design was acquired through data analysis, and the colors of historical landscape buildings were integrated with the colors of modern science and technology elements. With the introduction of building graphs, the deep connection between color design and brand visual image was enhanced (Fig. 4).

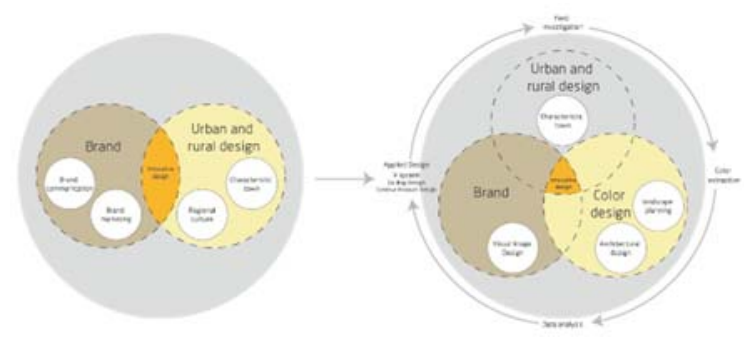

Figure 4: The research thoughts

(1) Literature retrieval methods: Based on books, journals and online databases, we searched the articles related to the characteristic town construction inside and outside China, and focused on the articles concerning brand building, visual image design and colors, which were the theoretical support of this study, and we also searched for the historical unity and coherence of Xiaolan characteristic town.

(2) Field investigation: Based on field investigation and research in Xiaolan characteristic town, we grasped the details of Xiaolan comprehensive regional landscape design and historic buildings, and acquired the real color data through photographing, exploration, visits and recording.

(3) Statistical analysis: The investigation and pictures of Xiaolan landscape architecture colors were summarized, sorted and inputted into a color management system (Microsoft Visual Foxpro), and together with the Munsell color system, analyzed the data and determined the color adaption range, which provide real and objective data for visual image design.

(4) Interdisciplinary research: The theories of industry and brand construction involved in this study are interdisciplinary. Moreover, the building of characteristic town brand color system was explored from multidimensional aspects based on theories of urban landscape building design and color psychology.

\section{Procedure}

\subsection{Material collection and screening}

Regional landscape is the main composition element of characteristic town visual image and is enriched with the characteristic town culture values. Characteristic towns are an important platform of urban development, and their landscape planning and historical building design also fully reflect the unique and diverse cultural characteristics. Thus, the colors of natural landscape plants and historical buildings in the core zone of Xiaolan were studied here, and samples were collected through field investigation and literature searching.

\subsection{Color quantitative analysis: extraction and establishment of color library}

(1) The color analysis system was constructed via a mathematical method on Microsoft Visual Foxpro. Firstly, the architectural colors in the core zone of Xiaolan were analyzed; then colors were extracted according to color landscape axis and the colors of natural landscape plants were summarized. Al statistical data were inputted to Microsoft Visual Foxpro so as to determine the proportion of each object. Based on these data, the landscape architecture color composition images in the core zone were plotted on Photoshop and Illustrator. The data were displayed as follows: the historical buildings, modern buildings and natural landscape were marked yellow, blue and green, respectively. Then the area proportions of these three types of data were macroscopically displayed, and thereby the proportional relationships among different types of landscape architectures in the core zone of Xiaolan were analyzed (Fig. 5). 


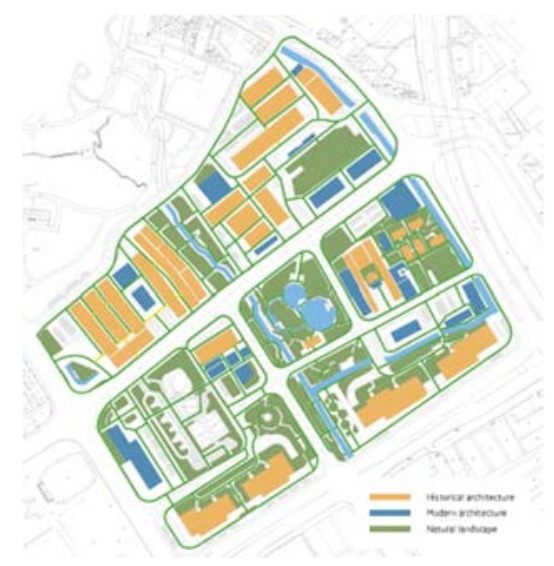

Figure 5: Proportions of historical buildings, modern architecture and natural landscape

(2) The color masses and the borders on the maps were unified on Microsoft Visual Foxpro. The hues of the basic colors can be relatively easily extracted. To present a more obvious change, we only considered the of contrast and brightness of hues. The hues of different attributes were determined, and the color brightness gradient function was conducted; then the ideal building color map and the ideal natural landscape color map of Xiaolan were generated (Fig. 6).

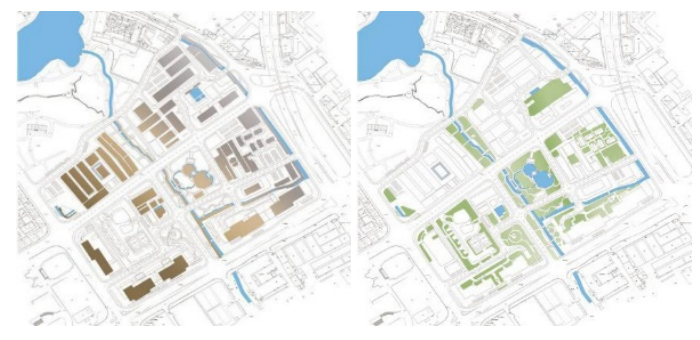

Figure 6: The ideal color maps of buildings and natural landscape in Xiaolan

(3) From the ideal color maps, we can determine the basic distribution and colors of buildings in the core zone of Xiaolan, which were dominated by gray and yellow. Thereby, through the color analysis system, the bar charts of proportions were plotted (Fig. 7).

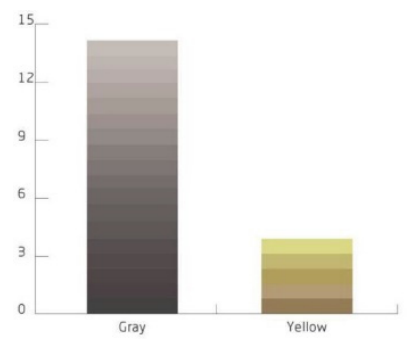

Figure 7: Bar chart of building colors

(4) According to the plant color values determined from investigation as well as the ideal natural landscape color map of Xiaolan, we compared the color data by using the Munsell color system and thereby clearly displayed the coloring of natural landscape plants in the core area of Xiaolan (Fig. 8).

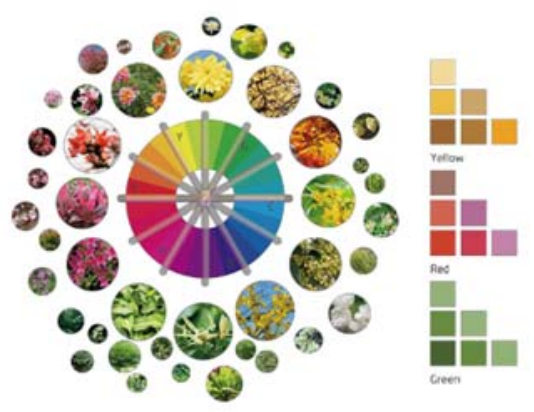

Figure 8: Colors of natural landscape plants

\subsection{The visual image design of brand}

(1) Design of basic parts. The name of Xiaolan was inspired by its olive-like shape and the fame of chrysanthemum. Thus, the Xiaolan chrysanthemum was integrated with technological industry elements. Together with the natural landscape plant coloring map, we designed the overall logo of Xiaolan with a sufficient sense of technology (Fig. 9). By importing the 6-functionzone division after architecture planning, we integrated the Lingnan cultural elements and historical building characteristics, and together with the building and natural landscape coloring maps, we carried out graphic design and auxiliary graphic design that highlight the distinctive cultures of chrysanthemum town of Xiaolan (Fig. 10).

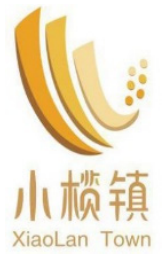

Figure 9: Logo of Xiaolan Town

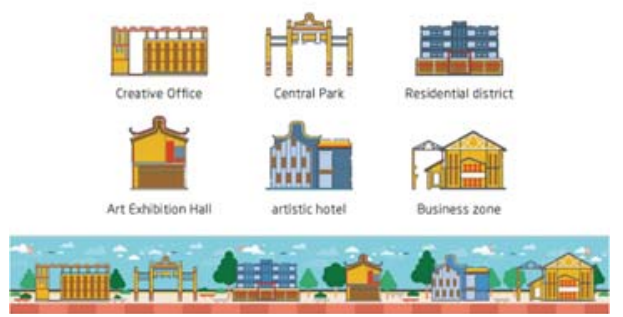

Figure 10: Graphic innovative design

(2) Orientation system design The orientation in the central park of the core zone of Xiaolan characteristic town was systemically designed. Firstly, based on the main color tone of Xiaolan and together with the warm yellow plants assisted with the metal colors of buildings, we designed the ikon. Then according to the orientation demands at different levels, we designed the orientation plates and finally applied into the concrete scenes (Fig. 11). 


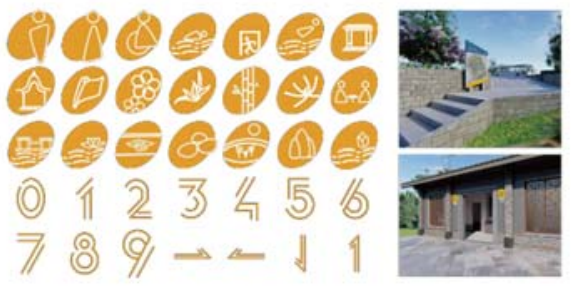

Figure 11: Orientation system design

(1) Application design The patterns of buildings in the 6 functional zones were organized and expanded through the divergent thinking into a series of souvenirs, including hold pillows, bookmark pens, card sticks, umbrellas, eyeshade, paper tapes, mobile phone support, red envelopes and folders (Fig. 12).

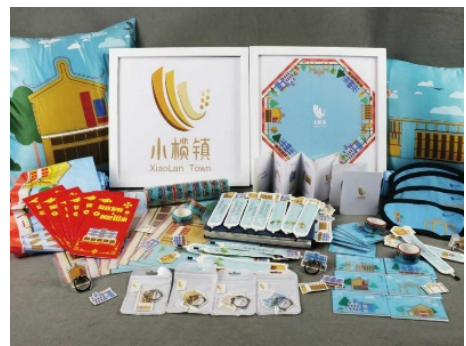

Figure 12: The designed objects from the application system

\subsection{Results}

(1) Color design serves the brand visual image design. Among the visual elements, colors compared with texts and forms are more aggressive, and appropriate color choices can impact the visual organs of the audience and thereby affect their psychological activities and aesthetic demand. The color application in brand visual image manufacturing can bring the audience different mental feelings. The colors are in the service of the theme and innovation of brand visual image design, and not only beautify and optimize pictures, but also convey different thoughts and feelings and create a better product image to consumer groups.

(2) Color design can better highlight the brand visual image of characteristic towns. The effective application of colors brings out the culture connotations of a characteristic town, can visually better display the products in front of consumer groups, and enhance the purchase motivation of consumers, which thereby broaden the consumer market.

\section{Conclusions}

(1) The brand visual image based on color design directly reflects the regional cultures and overall styles/features of a characteristic town and shows the diversity of landscape and building planning. The brand visual image based on the colors extracted from the regional landscape and buildings in Xiaolan characteristic town was studied, which reflected the rich chrysanthemum cultures and the characteristics of Lingnan landscape cultures in Xiaolan and thereby promoted the quality and connotation of its independent brand.

(2) Emphasis should be paid on the application of color elements to generate a stronger visual impact. The appropriate and combined use of colors can improve the visual image of characteristic town brands and enhance the visual impression of consumer groups on the characteristic town brands, which indirectly stimulated the increment of product sales and accelerated the industrial development.

(3) From the perspective of cultural heritage protection, the local landscape architecture colors were combined with the characteristic town brand visual design, which promoted the recreation of local cultures and enhanced the emotional recognition of regional cultures by the audience. Because of continual advances in science and technology, cultures and emotion are still needed by the rapidly- developing technology today. The contradiction between regional cultures and modern technology can be solved by the re-innovation of historical regional cultures and emotions in the inheritance process.

\section{FUNDING}

(1) Research on the Regeneration of Regional Folk Art Creative Industry from the Perspective of Cultural and Creative Industry supported by Jiangsu Postdoctoral Fund (Project No.: 1601192B).

(2) Jiangsu Graduate Scientific Research Innovation Plan "Research on Cultural and Creative Design in Jiangsu Based on integration of Historical and Cultural Resources" (Project No.: SJKY19_2524).

\section{REFERENCES}

1. Erik, B., \& Jasper, E. (2014). The effectiveness of place brand communication. Cities, 5(7), 64-70.

2. Stella, K., \& Mihalis, K. (2017). The role of brand elements in destination branding. Journal of Destination Marketing \& Management, 6(11), 426435.

3. Daniel, A. Levinthal, \& Massimo Warglien. (1999). Landscape Design: Designing for Local Action in Complex Worlds. Organization Science, 10(3), 342357.

4. Valtenbergs, V. González A, \& Piziks, R. (2013). Selecting indicators for sustainable development of small towns: The case of Valmiera municipality. Procedia Computer Science, 12(4), 21-32.

5. Shu, Z., \& Jun, L. (2013). Visual City's colour design:Taking the studying of wuhan city colour as an Example. Civil, Materials and Environmental Sciences, 4(6), 127-130.

6. Watanabe,Y. (2010). The Basis and Practice of Colorology. Beijing:China Architecture \& Building Press.

7. Verena, M.(2005). Colour as Vocation:Werner Spillmann's Contribution to Environment Color Design. CLOR research and application, 30(1),53-65. 
8. Jose, C.(2006).Research on Color in Architecture and Environmental Design: Brief History, Current Developments, and Possible Future. CLOR research and application, 31(4),350-363.

9. Vosinakis, S., \& Koutsabasis, P.(2008). Virtual environments for collaborative design: requirements and guidelines from a social action perspective. Co Design. 5(2), 17-18.

10. Maria, L.,\& Mattiello,F.(2011).Colours in La Boca:Patrimonial Identity in the Urban Landscape. CLOR research and application, 36(3),223-228.

11. Filareti, K., \& Melodena, S. (2018). Place branding: Aligning multiple stakeholder perception of visual and auditory communication elements. Journal of Destination Marketing \& Management, 8(6), 112130.

12. Krieger, A., \& Saunders, W. (2009). Urban design. Minneapolis: University of Minnesota Press.

13. Yacine, G.,Abdelkader,M \& Racha G.(2018). A novel method for assessing the chromatic integration of architecture in the Ksourian landscape of M'zab Valley, Algeria. Color Research \& Application, 43(5), 760-778.

14. Yuning Cheng., \& Ming Tan. (2018). The quantitative research of landscape color: A study of Ming Dynasty City Wall in Nanjing. Color Research \& Application, 43(3), 436-448. 